\title{
Optimization of the quenching method for metabolomics analysis of Lactobacillus bulgaricus"
}

\author{
Ming-ming $\mathrm{CHEN}^{1}$, Ai-li $\mathrm{LI}^{\dagger+1}$, Mao-cheng $\mathrm{SUN}^{2}$, Zhen $\mathrm{FENG}^{1}$, Xiang-chen MENG ${ }^{1}$, Ying WANG ${ }^{1}$ \\ ( ${ }^{1}$ MOE Key Laboratory of Dairy Science, College of Food Science, Northeast Agricultural University, Harbin 150030, China) \\ $\left({ }^{2}\right.$ School of Public Health, Jilin Medical College, Jilin 132013, China) \\ †E-mail: aili-mail@163.com
}

Received May 24, 2013; Revision accepted Nov. 18, 2013; Crosschecked Mar. 18, 2014

\begin{abstract}
This study proposed a quenching protocol for metabolite analysis of Lactobacillus delbrueckii subsp. bulgaricus. Microbial cells were quenched with $60 \%$ methanol/water, $80 \%$ methanol/glycerol, or $80 \%$ methanol/water. The effect of the quenching process was assessed by the optical density (OD)-based method, flow cytometry, and gas chromatography-mass spectrometry (GC-MS). The principal component analysis (PCA) and orthogonal partial least squares-discriminant analysis (OPLS-DA) were employed for metabolite identification. The results indicated that quenching with $80 \%$ methanol/water solution led to less damage to the $L$. bulgaricus cells, characterized by the lower relative fraction of prodium iodide (PI)-labeled cells and the higher OD recovery ratio. Through GC-MS analysis, higher levels of intracellular metabolites (including focal glutamic acid, aspartic acid, alanine, and AMP) and a lower leakage rate were detected in the sample quenched with $80 \%$ methanol/water compared with the others. In conclusion, we suggested a higher concentration of cold methanol quenching for $L$. bulgaricus metabolomics due to its decreasing metabolite leakage.
\end{abstract}

Key words: Metabolomics, Quenching method, Lactobacillus bulgaricus, Leakage doi:10.1631/jzus.B1300149

Document code: A

CLC number: Q819

\section{Introduction}

Lactobacillus delbrueckii subsp. bulgaricus is an important lactobacillus commonly used for fermented milk products (Garbayo et al., 2004; Schiraldi et al., 2006; Li et al., 2009). The metabolic capacities of $L$. bulgaricus were responsible for the development of milk acidification and formations of texture and aroma (Russell and Diez-Gonzalez, 1998; Siegumfeldt et al., 2000). However, a traditional biochemistry method was difficult to effectively identify and

\footnotetext{
${ }^{\ddagger}$ Corresponding author

* Project supported by the Open Research Fund for the MOE Key Laboratory of Dairy Science (No. 2012KLDSOF-07), the National Natural Science Foundation of China (No. 31000808), the Synergetic Innovation Center of Food Safety and Nutrition, and the Open Research Fund of Northeast Agricultural University, China (C) Zhejiang University and Springer-Verlag Berlin Heidelberg 2014
}

quantify the intracellular metabolites of the bacteria (Nielsen, 1997; Schaefer et al., 1999; Lange et al., 2001). Recently, rapidly growing reports demonstrated that microbial metabolomics could provide more data and describe higher complex metabolite profiles (Oldiges et al., 2007; Wu et al., 2008; Tang et al., 2009). Typical detection methods in metabolome analysis include gas chromatography-mass spectrometry (GC-MS), liquid chromatography (LC)-MS, and nuclear magnetic resonance spectroscopy (NMR), which offer higher sensitivity and the ability to detect a larger number of low-molecular weight metabolites (van Dam et al., 2002; Coulier et al., 2006; Koek et al., 2006). Accordingly, further studies on metabolomics could contribute to a better understanding on the necessary role of L. bulgaricus in fermentation.

L. bulgaricus metabolomics requires efficient and reliable quenching and extracting methods. Cold 
methanol-water quenching was considered as a general procedure to rapidly inactivate bacteria metabolism, which has been widely applied to Escherichia coli, Staphylococcus aureus, and yeast (Castrillo et al. 2003; Jana et al., 2009; Meyer et al., 2010). The effect of methanol quenching on the leakage of intracellular metabolites has been widely studied. Wittmann et al. (2004) showed that a lower concentration of methanol quenching significantly reduced the leakage of metabolites in Corynebacterium glutamicum. However, Canelas et al. (2008) proposed that the intracellular components of Saccharomyces cerevisiae could be effectively protected by quenching in $80 \%$ methanol. Link et al. (2008) observed that methanol-glycerol quenching fluid showed lower leakage compared to methanol-water quenching fluid. In addition, many studies focused on the effect of quenching on the cell membrane integrity. Schädel et al. (2011) used an optical density (OD)-based method and flow cytometry to investigate the cell damage in $E$. coli during quenching. However, few studies reported on the quenching method for lactobacillus metabolomics analysis.

This study aimed to examine different quenching solutions for the investigation of the L. bulgaricus metabolomics. The optimized quenching processing for L. bulgaricus would be applicable for other lactobacillus.

\section{Materials and methods}

\subsection{Bacterial strain and growth conditions}

L. bulgaricus ATCC 11842 was obtained from the American Type Culture Collection. The bacteria were cultivated in a 3.7-L laboratory fermenter (Bio-Rad, Switzerland) at $37{ }^{\circ} \mathrm{C}, 200 \mathrm{r} / \mathrm{min}$, and $\mathrm{pH}$ $6.2 \pm 0.2$ until the cells reached the stationary phase. The chemically defined medium was prepared in accordance with Otto et al. (1983).

\subsection{Quenching process}

Three quenching fluids were prepared: $60 \%$ methanol/water (Meth), $80 \%$ methanol/glycerol (Meth/gly), and 80\% Meth.

The bacteria cells of $L$. bulgaricus were collected by centrifugation at $7000 \mathrm{~g}$ for $5 \mathrm{~min}$ at $4{ }^{\circ} \mathrm{C}$. Subsequently, re-suspended cells were washed twice with $0.9 \%$ saline solution at $4{ }^{\circ} \mathrm{C}$. The samples were then quenched with $5 \mathrm{ml}$ of three different methanol liquids respectively, followed by being vortex-mixed and centrifuged at $10000 \mathrm{~g}$ for $5 \mathrm{~min}$ at $-20^{\circ} \mathrm{C}$.

The supernatants were removed quickly and used as extracellular samples for analyzing the leakage of intracellular metabolites. Simultaneously, the quenched bacteria cells were extracted by $2 \mathrm{ml}$ boiling ethanol/water $(3: 1, \mathrm{v} / \mathrm{v})$ solution $\left(95^{\circ} \mathrm{C}\right)$ according to Faijes et al. (2007). After that, the preparations were centrifugated $\left(10000 \mathrm{~g}, 5 \mathrm{~min},-20^{\circ} \mathrm{C}\right)$, and the supernatant was frozen at $-80{ }^{\circ} \mathrm{C}$ and used as an intracellular sample for analyzing the metabolite levels in L. bulgaricus.

\subsection{Cell leakage test}

OD recovery ratio was used to quantify the whole cell damage (Schädel et al., 2011), which was calculated as the $\mathrm{OD}$ value at $660 \mathrm{~nm}\left(\mathrm{OD}_{660}\right)$ of untreated sample/ $\mathrm{OD}_{660}$ of treated sample). Briefly, the $\mathrm{OD}_{660}$ values of untreated samples were first monitored using a spectrophotometer (Beckman Coulter, Germany). Subsequently, the quenched cell pellets were re-suspended in $4 \mathrm{ml}$ phosphate buffered saline (PBS), which allowed for detecting the decrease of $\mathrm{OD}_{660}$ of the cell suspensions.

Flow cytometry was used for quantitative analysis of single cell damage (Schädel et al., 2011). The quenched cell suspensions, added with $10 \mu \mathrm{l} / \mathrm{ml}$ prodium iodide (PI) staining solution, were mixed gently and incubated for $4 \mathrm{~min}$ in the dark. The PI fluorescence was detected (using the FL-2 or FL-3 channel) by a flow cytometer (BD Bioscience, USA). The data of unstained cells (intact cell membrane) and singlecolor positive cells (damaged cell membrane) were obtained for quantifying the undamaged and damaged cells.

\subsection{Evaluation of quenching protocols by gas chromatography-mass spectrometry (GC-MS)}

Metabolites extracted from the L. bulgaricus were tested by GC-MS analysis. Firstly, $10 \mu \mathrm{l}$ of ${ }^{13} \mathrm{C}_{6}$-leucine $(20 \mu \mathrm{g} / \mathrm{ml})$ was added into each of the $200 \mu \mathrm{l}$ re-dissolved samples. Then, the solution was mixed for $5 \mathrm{~s}$ and dried under nitrogen gas at $50{ }^{\circ} \mathrm{C}$ for $30 \mathrm{~min}$. Subsequently, the sample was transferred to a GC vial and $30 \mu \mathrm{l}$ of $20 \mathrm{mg} / \mathrm{ml}$ methoxy amine pyridine hydrochloride was added, mixed for $30 \mathrm{~s}$ and oxidated at $37^{\circ} \mathrm{C}$ for $90 \mathrm{~min}$. $\mathrm{N}, \mathrm{O}$-bis(trimethylsily) 
trifluoractamide (BSTFA) of a volume of $30 \mu \mathrm{l}$ containing $1 \%(\mathrm{v} / \mathrm{v})$ trimethylchlorosilane (TMCS) was added to each vial and the mixture was incubated for 30 min at $70{ }^{\circ} \mathrm{C}$. Ultimately, a devitalized sample was kept at room temperature for $30 \mathrm{~min}$.

Agilent 7890A/5975C GC/MS, including an HP$5 \mathrm{MS}$ fused silica capillary column $(30 \mathrm{~m} \times 0.25 \mathrm{~mm} \times$ $0.25 \mu \mathrm{m})$ was used for metabolite analysis. The injector temperature was set at $280{ }^{\circ} \mathrm{C}$. The electronic ignition (EI) ion source temperature was set at $230^{\circ} \mathrm{C}$ Helium $(99.999 \%)$ was used as a carrier gas at a flow rate of $1.0 \mathrm{ml} / \mathrm{min}$, and $1-\mu \mathrm{l}$ sample was injected in a spoutless mode. The column temperature was first kept at $80{ }^{\circ} \mathrm{C}$ for $2 \mathrm{~min}$, increased to $320^{\circ} \mathrm{C}$ at a rate of $10{ }^{\circ} \mathrm{C} / \mathrm{min}$ and maintained for $6 \mathrm{~min}$. The mass spectrometer was operated in the scan mode at the mass range of $50-550 \mathrm{~m} / \mathrm{z}$.

\subsection{Statistical analysis}

After GC-MS analysis, statistical preprocessing was performed using XCMS software (https:// xcmsonline.scripps.edu/?) under an $R$ platform and later edited in Microsoft Excel 2010. Impurity peaks produced from sample preparation and column bleeding were wiped out, and all results containing variables, peak-area, and observables are organized into a 2D matrix. The preprocessed GC-MS data were then imported into Simca-P software (Version 11.0) and principal component analysis (PCA) and orthogonal partial least squares-discriminant analysis (OPLS-DA) were executed. PCA was used to differentiate the samples. OPLS-DA analysis was used to filter the quadrature signal. The efficiencies of the models were determined by values of $R^{2}$ and $Q^{2}$. In addition, permutation tests were performed to test the validity of the OPLS-DA models. Statistical significance was evaluated using the $t$-test and $P<0.1$ was considered significant.

\section{Results}

\subsection{Impact of quenching protocols on single cell damage}

The PI dye can bind to nucleic acids inside the cells and then form a red fluorescent signal, which can be detected by flow cytometry (Díaz et al., 2010). Thus, the PI-staining method was applied to examine the degree of damage to the cells after the aqueous methanol quenching.

Because PI is a membrane impermeant dye, the cell without treating and quenching had relatively intact membranes and exhibited a 3\% PI labeling (Figs. 1 and 2). The variation of the composition of methanol solutions changed the ratio of PI-labeled cells. Compared with the $60 \%$ Meth quenching, the $80 \%$ Meth quenching caused less damage to the L. bulgaricus cells. In addition, the $80 \%$ Meth/gly effectively protected the cell membranes and reduced the ratio of PI labeling to $6.6 \%$, which was significantly less than that in the Meth quenching $(P<0.05)$.

\subsection{Impact of quenching protocols on whole cell damage}

We further analyzed the total cell rupture by monitoring the reduction of $\mathrm{OD}_{660}$ in the quenching samples (Fig. 3). It was found that the $\mathrm{OD}_{660}$ recovery ratio of the cold $80 \%$ Meth/gly was higher than those of other quenching methods, which indicated that Meth/gly had a positive effect on preventing the $L$. bulgaricus cell lyses.

The $\mathrm{OD}_{660}$ recovery ratio of $80 \%$ Meth quenching was higher than that of $60 \%$ Meth quenching $(P>0.05)$. The result also indicated that adoption of $80 \%$ Meth as a quenching fluid could decrease the cell rupture.

\subsection{Evaluation of intracellular metabolite profiles of $L$. bulgaricus}

The results of GC-MS showed that there was a strong signal with good sensitivity and reproducibility in the GC-MS total ion chromatograms (TICs) of all samples. However, other peak areas of the $80 \%$ Meth/gly chromatogram were covered due to a saturated peak glycerol present at $8.55 \mathrm{~min}$ of retention time (Fig. 4b). It respectively found 807,603 , and 841 substances in the GC/MS TICs of $60 \%$ Meth, $80 \%$ Meth/gly, and 80\% Meth samples, including ATP and its derivatives, amino acids, organic acids, sugars, and fatty acids (Fig. 4).

The PCA score plot showed that the samples prepared by different methanols were clearly separated, although $80 \%$ Meth/gly and $80 \%$ Meth were grouped closely (Fig. 5a). Detailed insight into the differences can be identified by examining the PCA loading plot (Fig. 5b). The major compounds that 
(a)

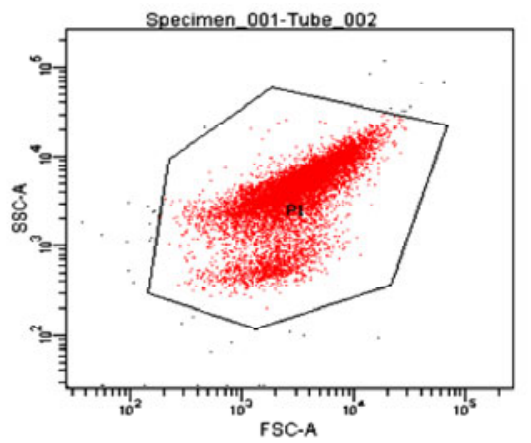

(b)

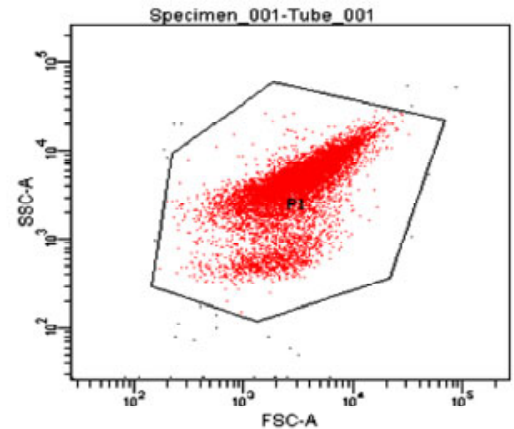

(c)

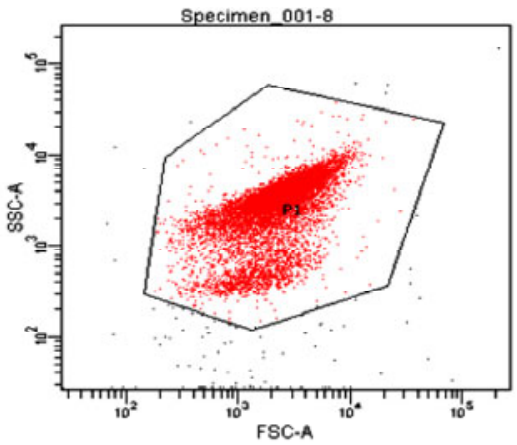

(d)

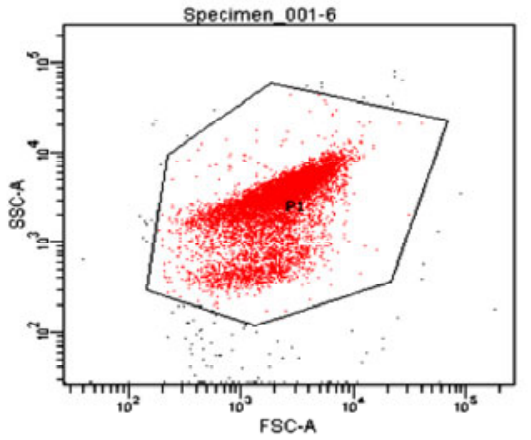

(e)

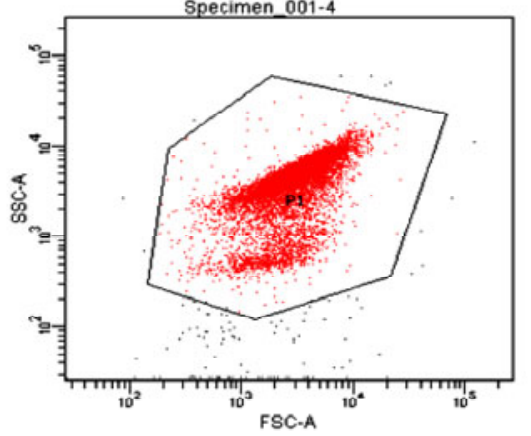

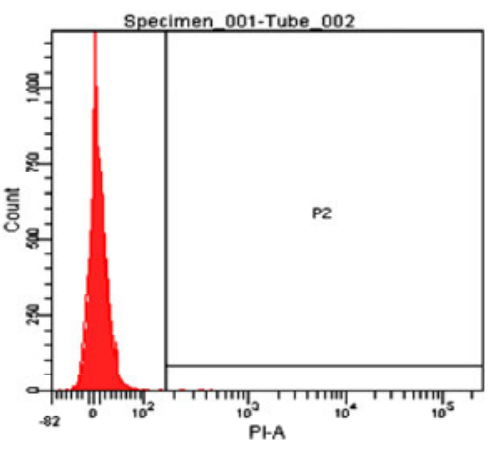
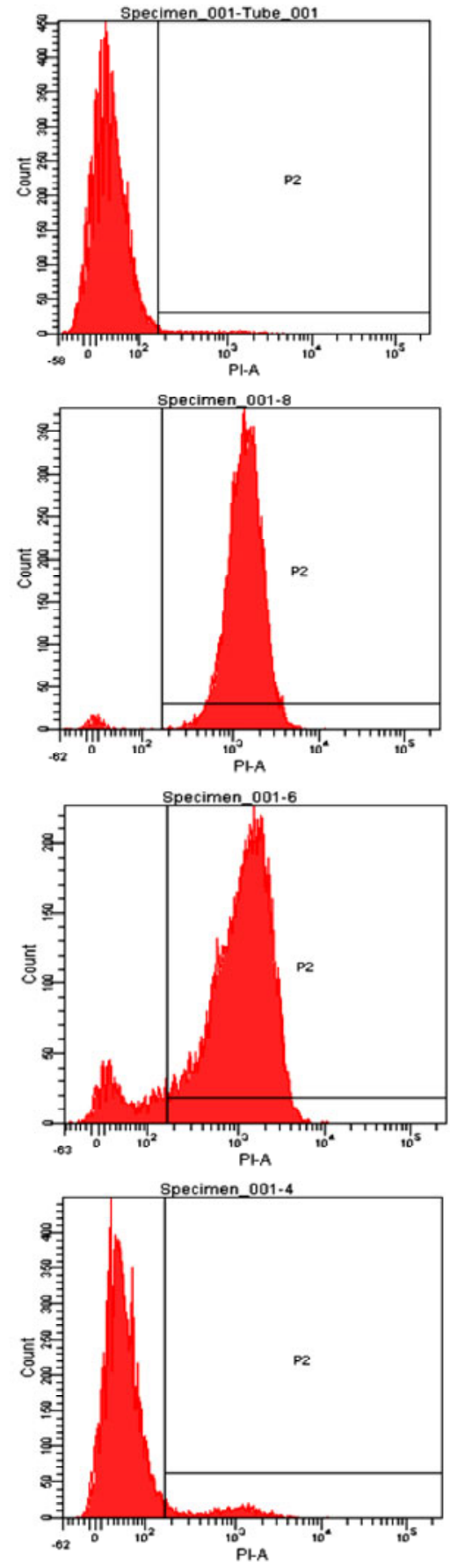

Fig. 1 Flow cytometry diagrams for evaluation of the cell membrane integrity

Unquenched samples without (a) and with (b) PI staining. Quenched samples by $60 \%$ Meth (c), $80 \%$ Meth (d), and $80 \%$ Meth/gly (e) 


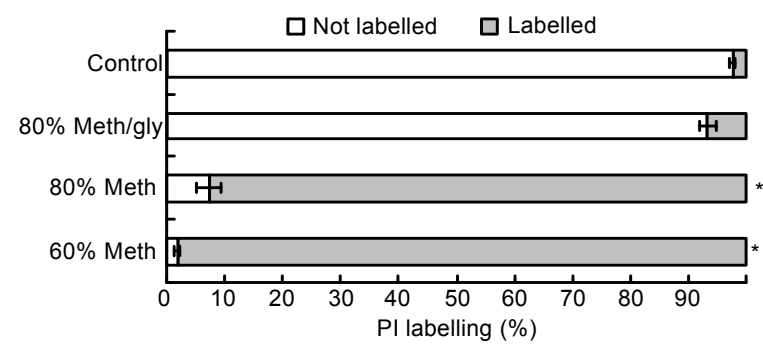

Fig. 2 Percentages of PI labelling of different quenching treatments

Data are expressed as mean $\pm \mathrm{SD}(n=5) .{ }^{*} P<0.05$ vs. control cells

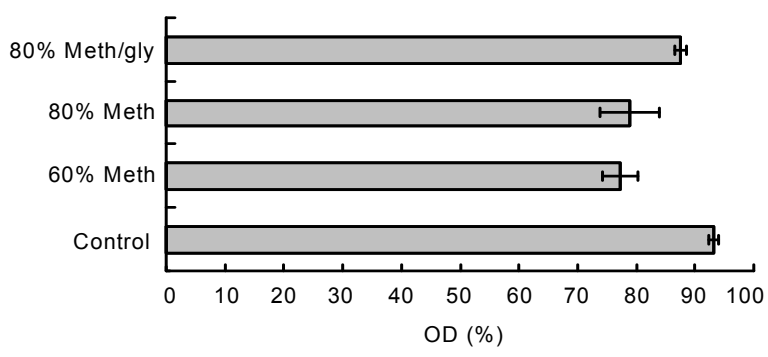

Fig. 3 OD recovery ratios of different quenching treatments

Data are expressed as mean $\pm \mathrm{SD}(n=5)$
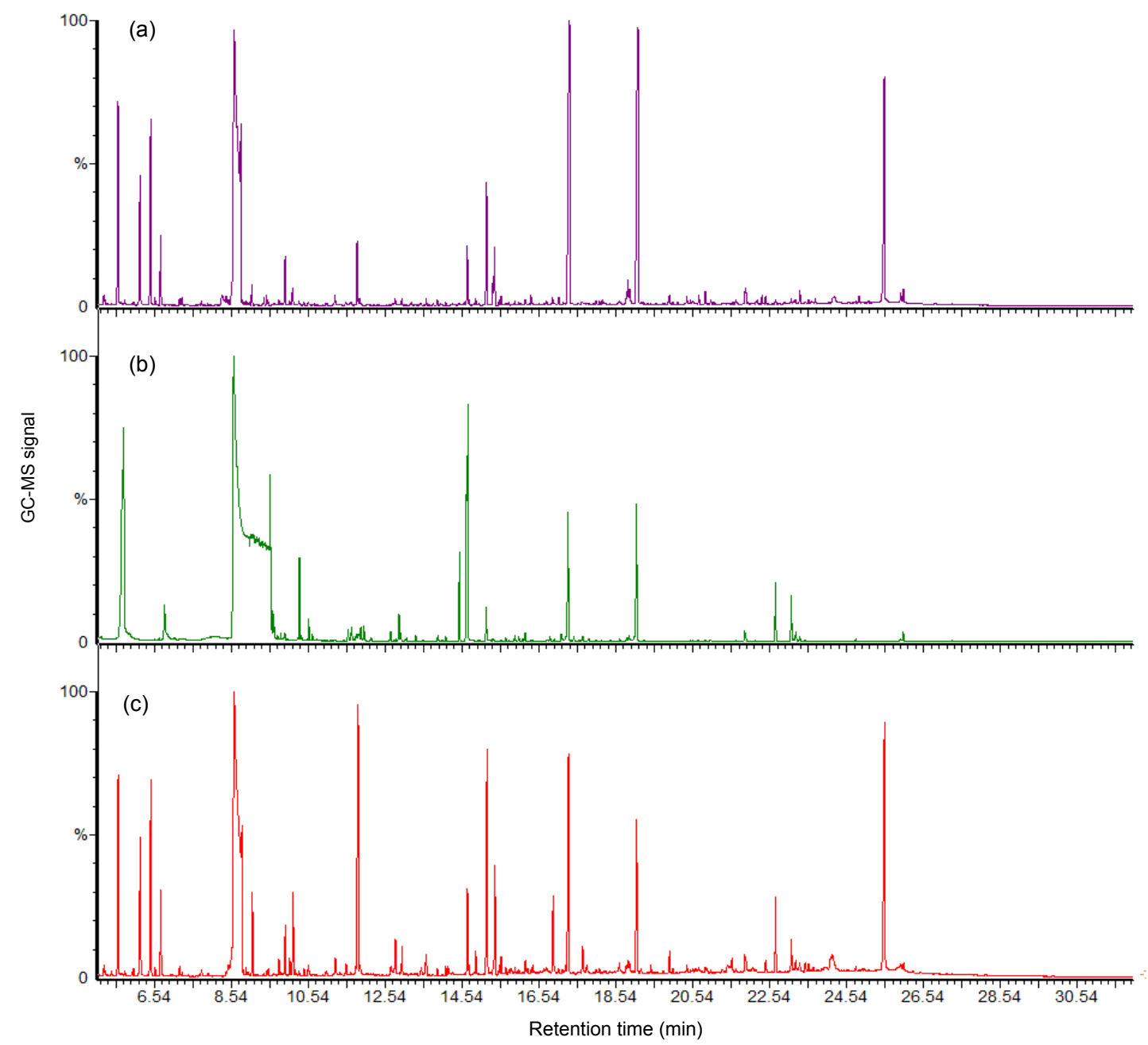

Fig. 4 GC-MS total ion chromatograms (TICs) of intracellular metabolite profiles of $L$. bulgaricus from three methanol quenching groups: (a) 60\% Meth; (b) 80\% Meth/gly; (c) 80\% Meth

contributed to the discrimination of $60 \%$ Meth samples were palmitic acid and stearic acid. Moreover, focal glutamic acid, aspartic acid, alanine, and AMP were the metabolites which contributed to the separation of the $80 \%$ Meth samples from others. It is suggested that the $80 \%$ Meth quenching method was superior to quenching with $60 \%$ Meth and $80 \%$ Meth/gly, because larger amounts of metabolites were detected. 

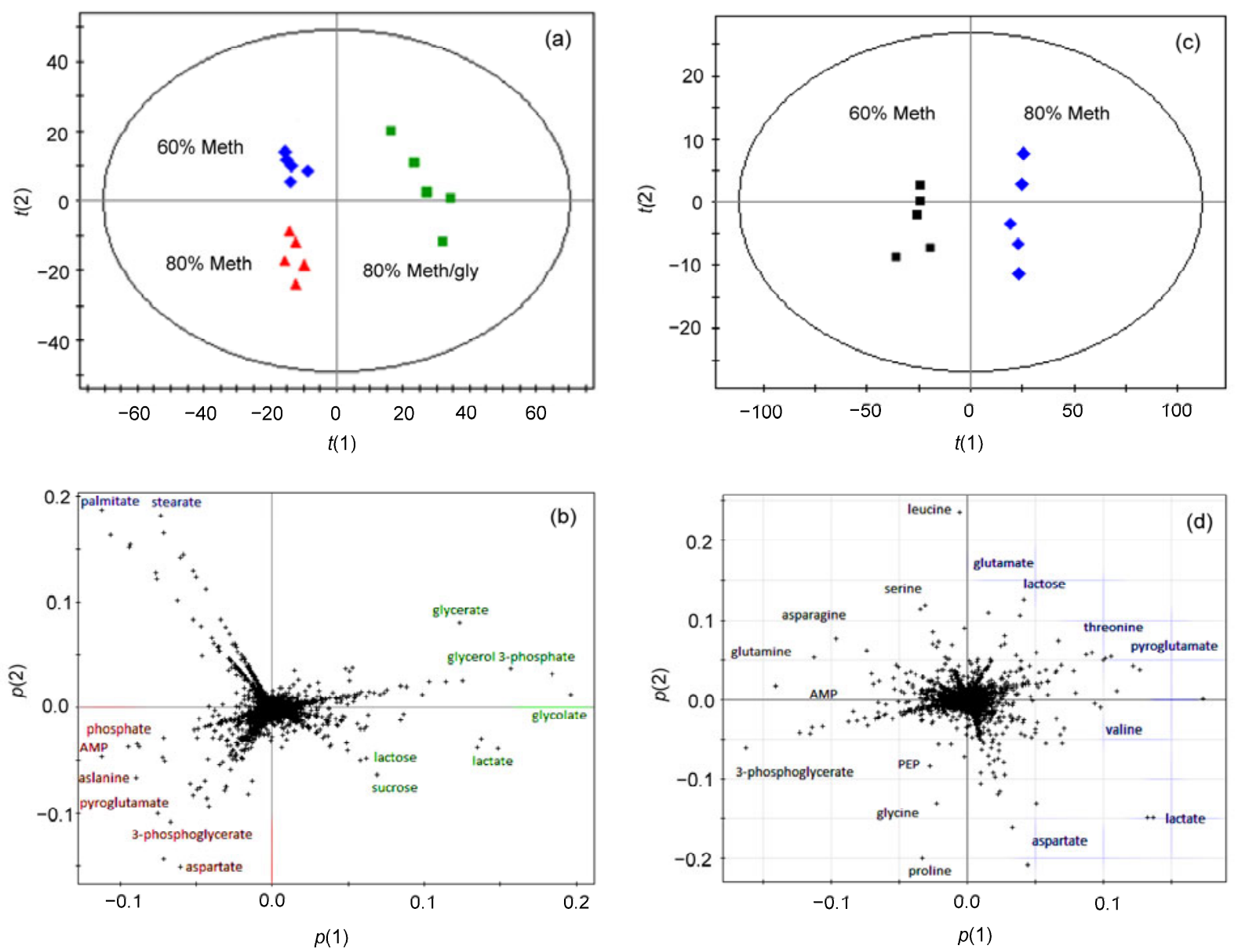

Fig. 5 Comparison of three quenching methods by multivariate statistical analysis

PCA score plot (a) and loading plot (b) from the GC-MS spectra originated from intracellular metabolite profiles of $L$. bulgaricus quenched by different methanol fluids. PCA score plot (c) and loading plot (d) from the GC-MS spectra originated from extracellular metabolite profiles of $L$. bulgaricus quenched by different methanol fluids. In the score plot, $t(1)$ and $t(2)$ are the $X$ scores for the two predictive components, and the loading plot shows the loadings for both $X$ and $Y$ in the form of $p(1)$ and $p(2)$

\subsection{Evaluation of extracellular metabolite profiles of $L$. bulgaricus}

Since L. bulgaricus cells were sensitive to methanol quenching procedures so as to lose their intracellular metabolites, the concentrations of extracellular (supernatant) metabolite were also measured by GC-MS.

The PCA score plot in Fig. 5c showed that the supernatant metabolites of $60 \%$ and $80 \%$ Meth groups were clearly separated, which was in accordance with the high $R^{2} X$ value of 0.834 and $Q^{2}$ value of 0.56 . It indicated that the prediction performance of PCA models was good. A few kinds of metabolites in the two quenched supernatants were significantly different (Fig. 5d). Asparagine, serine, AMP, and phosphoenolpyruvate (PEP) were presented in the supernatant of the $60 \%$ Meth group. The metabolites in the supernatant of the $80 \%$ Meth group were mainly glutamic acid, valine, threonine, and aspartate.

\subsection{Impact of quenching protocols on the meta- bolitic profiles}

The differences between the extracellular and intracellular metabolite samples were examined by OPLS-DA. The OPLS-DA score plot for the extracellular and intracellular substances of the $60 \%$ Meth 


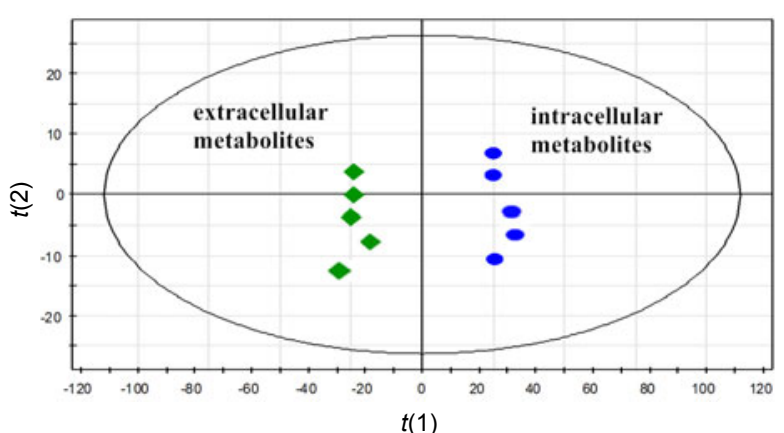

(a)

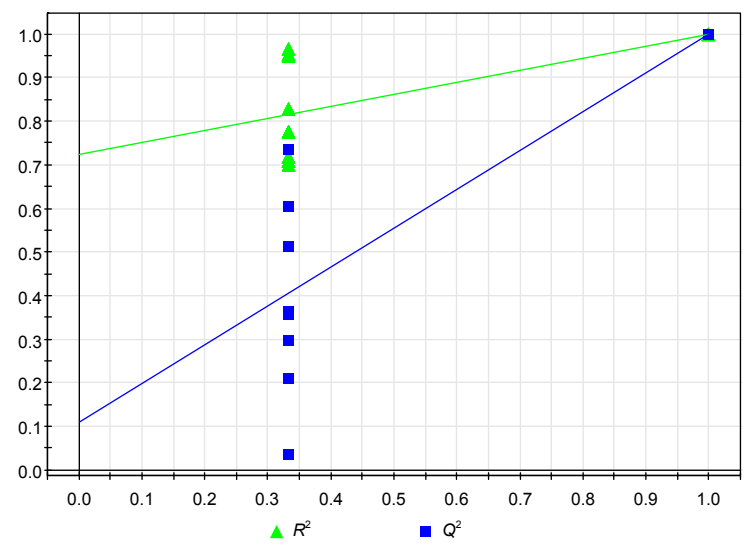

(c)

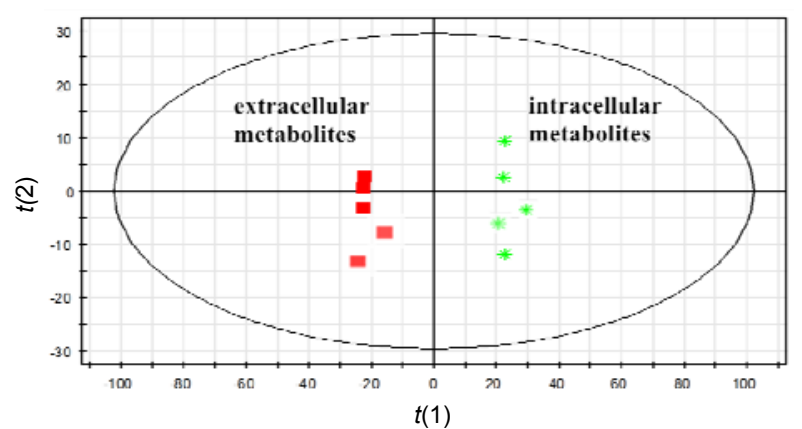

(b)

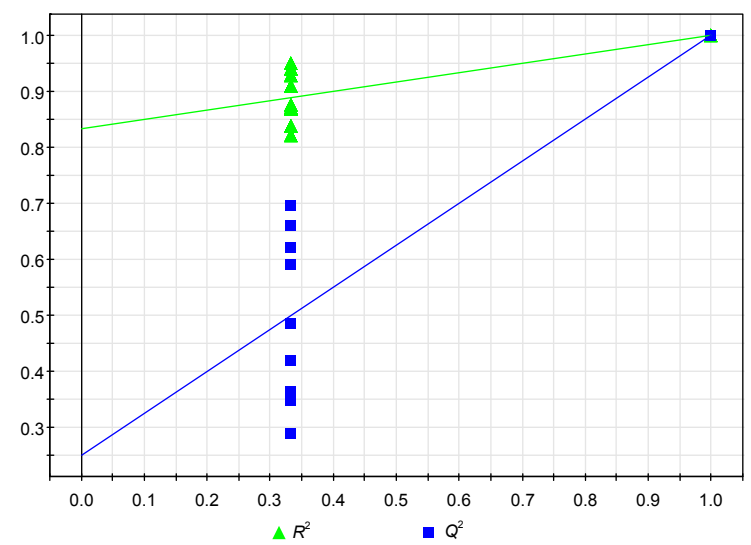

(d)

Fig. 6 OPLS-DA score plots demonstrating the differentiation in intracellular and extracellular metabolites samples OPLS-DA score plots of $60 \%$ Meth (a) and $80 \%$ Meth (b) quenching groups. Permutation tests for OPLS models of the $60 \%$ Meth (c) and $80 \%$ Meth (d) quenching groups. $t(1)$ and $t(2)$ are the $X$ scores for the two predictive components using supervision methods, and SIMCA-P displays the plot of the correlation coefficient between the original $Y$ and the permuted $Y$ versus the cumulative $R^{2}$ and $Q^{2}$, and draws the regression line, in which the intercept $\left(R^{2}\right.$ and $Q^{2}$ when correlation coefficient is zero) is a measure of the overfit

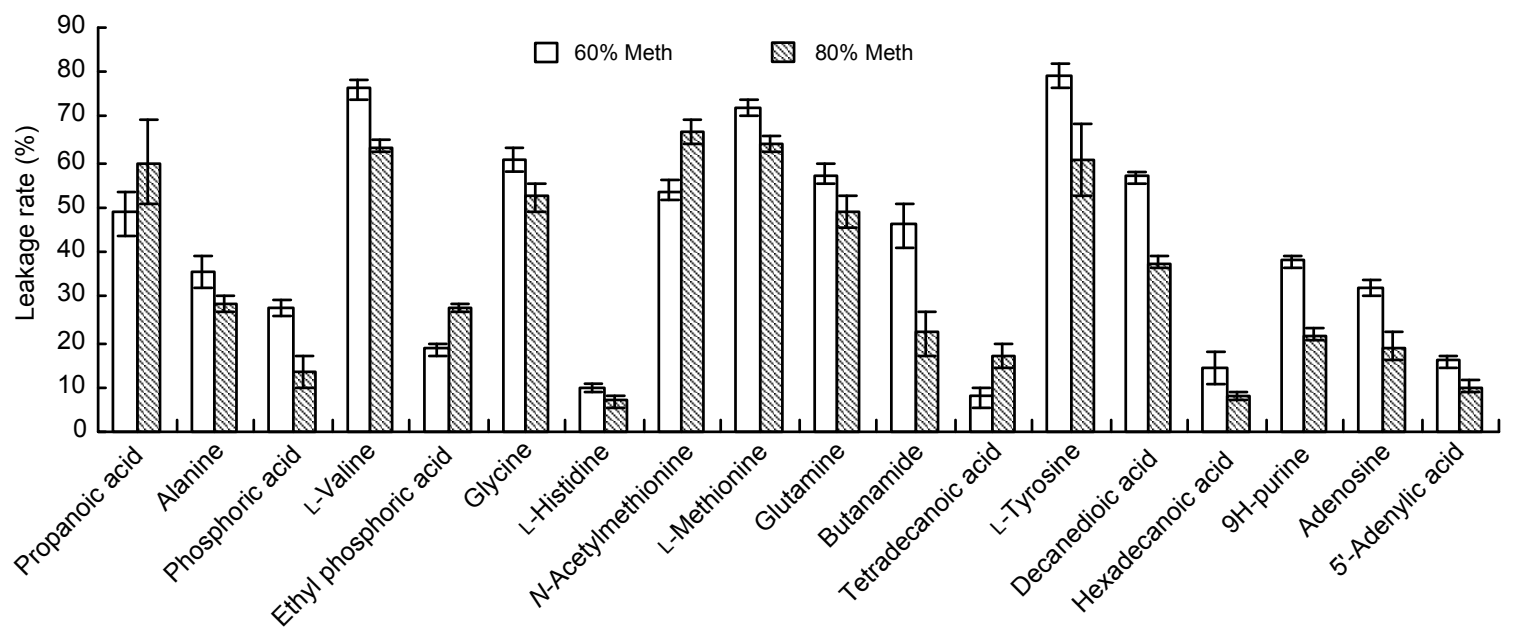

Fig. 7 Comparison of the leakage rates of metabolites caused by $60 \%$ and $80 \%$ cold methanol Data are expressed as mean $\pm \mathrm{SD}(n=5)$ 
quenching group (one orthogonal and two predictive components, $R^{2} X=0.941, R^{2} Y=1, Q^{2}=0.999$ ) and the extracellular and intracellular metabolites of the $80 \%$ Meth quenching group $\left(R^{2} X=0.901, R^{2} Y=1, Q^{2}=0.998\right)$ indicated that the two models were reliable and the metabolic samples had significant differences (Figs. 6a and 6b). Furthermore, the OPLS-DA models were validated with a permutation test (200 times). The results of the tests further verified the performance of the model showing that $Q^{2}$ was relatively high than $R^{2}$ (Figs. 6c and 6d).

The experimental results showed that 45 kinds of metabolites had significant differences between supernatant and intracellular substances from the $60 \%$ and $80 \%$ Meth quenching groups. Among them, 18 kinds of different metabolites were identified. According to the relative content of these metabolites, we were able to calculate the effect of the $60 \%$ and $80 \%$ Meth quenching on the leakage rate of intracellular metabolites in L. bulgaricus. As shown in Fig. 7, the leakage rates of cell metabolites affected by $80 \%$ Meth quenching were less than those affected by $60 \%$ Meth quenching. If $80 \%$ Meth was used for quenching, the leakage rates of the 14 kinds of metabolites were lower than those using the $60 \%$ Meth, such as alanine, glycine, and glutamine. However, the leakage rates of four kinds of metabolites, including propanoic acid, ethylphoric acid, $N$-acetylmethionine, and tetradecanoic acid, by $80 \%$ Meth quenching were higher than those by the cold $60 \%$ Meth quenching.

\section{Discussion}

Bacterial cells are sensitive to quenching solutions, which results in damage to the cell wall and membrane and the loss of intracellular metabolites (Duetz and Witholt, 2004; Kumar et al., 2004). Therefore, this study focused on comparing different methanol solutions, including 60\% Meth, 80\% Meth/gly, and 80\% Meth, for proposing an appropriate quenching protocol for L. bulgaricus.

Firstly, we evaluated the effects of quenching protocols on the membrane integrity and cell lysis by flow cytometry using PI dye and OD recovery ratio. It was found that increasing the methanol concentration or using the glycerol as a buffer was very effective for reducing cell membrane damage. Previous studies confirmed that both methanol and glycerol were effective cryoprotectants for L. bulgaricus and had the ability to enhance the cell viability against freezing damage (Carvalho et al., 2004; Fonseca et al., 2006). Especially, glycerol as a permeable compound could protect freeze-dried lactic acid bacteria through inhibiting excess dehydration, reducing salt toxicity, and preventing ice crystals formation (Huang et al., 2006). Recently, isosmotic glycerol solution was widely applied as a quenching agent to maintain osmotic pressure for bacterial cells (Villas-Bôas and Bruheim, 2007). This work found that $80 \%$ Meth/gly quenching could reduce the cell damage to L. bulgaricus. Hence, it is suggested that L. bulgaricus cells quenched in the presence of glycerol could effectively protect the stability of cell membrane.

Subsequently, the extracellular and intracellular metabolite profiles of L. bulgaricus affected by different quenching fluids were assessed based on GC-MS and PCA analytical methods. On the one hand, we found that it was difficult to remove the glycerol from the supernatant of quenched samples, which severely affected the results of the GC-MS analysis. Therefore, the data for the extracellular metabolite samples of $80 \%$ Meth/gly quenching were discarded. On the other hand, the GC-MS analysis of intracellular metabolite profiles revealed that 600 800 metabolite compounds were detected, in which 196 kinds of compounds were identified and 113 kinds of metabolites were represented. The effect of the methanol concentration on the levels of metabolite extracts was further evaluated. In accordance with the findings of Canelas et al. (2008), we showed consistently higher concentrations of intracellular metabolites from the samples treated with $80 \%$ Meth compared with $60 \%$ Meth. These results suggest that the $80 \%$ Meth, acting as a protective agent, could prevent the losses of metabolites from the cells.

Further, OPLS-DA was employed to investigate the differences between extracellular and intracellular metabolite profiles derived from different quenching methods. The reliabilities of the OPLS-DA models had been validated by permutation tests. The OPLSDA score plots showed a trend toward differentiating between supernatant and intracellular samples quenched with $60 \%$ or $80 \%$ Meth. In accordance with the previous studies, cold methanol quenching led to some metabolite losses from bacterial cells (Bolten 
et al., 2007; Spura et al., 2009). In our study, the supernatant sample of $80 \%$ Meth treatment contained lower concentrations of metabolites compared with the remaining intracellular concentrations. Furthermore, the leakage rate of the sample prepared using $80 \%$ Meth was lower than that of the $60 \%$ Meth group, suggesting that the $80 \%$ Meth quenching method is a preferable method for the analysis of the intracellular metabolites from L. bulgaricus.

\section{Conclusions}

In summary, quenching is a critical step in the evaluation of $L$. bulgaricus metabolomics. Compared to the general quenching in $60 \%$ cold methanol fluid, it is proposed that a $80 \%$ cold methanol or $80 \%$ cold methanol/glycerol solution was better for reducing the extent of leakage and examining higher concentrations of intracellular metabolites. The application of an optimized quenching process would contribute to identifying the specific biomarkers and also help to analyze the metabolic characteristics of $L$. bulgaricus.

\section{Compliance with ethics guidelines}

Ming-ming CHEN, Ai-li LI, Mao-cheng SUN, Zhen FENG, Xiang-chen MENG, and Ying WANG declare that they have no conflict of interest.

This article does not contain any studies with human or animal subjects performed by any of the authors.

\section{References}

Bolten, C.J., Kiefer, P., Letisse, F., et al., 2007. Sampling for metabolome analysis of microorganisms. Anal. Chem., 79(10):3843-3849. [doi:10.1021/ac0623888]

Canelas, A.B., Ras, C., ten Pierick, A., et al., 2008. Leakagefree rapid quenching technique for yeast metabolomics. Metabolomics, 4(3):226-239. [doi:10.1007/s11306-0080116-4]

Carvalho, A.S., Silva, J., Ho, P., et al., 2004. Relevant factors for the preparation of freeze-dried lactic acid bacteria. Int . Dairy J., 14(10):835-847. [doi:10.1016/j.idairyj.2004.02 . 001]

Castrillo, J.I., Hayes, A., Mohmmed, S., et al., 2003. An optimized protocol for metabolome analysis in yeast using direct infusion electrospray mass spectrometry. Phytochemistry, 62(6):929-937. [doi:10.1016/S0031-9422(02) 00713-6]

Coulier, L., Bas, R., Jespersen, S., et al., 2006. Simultaneous quantitative analysis of metabolites using ion-pair liquid chromatography-electrospray ionization mass spectro- metry. Anal. Biochem., 78(18):6573-6582. [doi:10.1021/ ac0607616]

Díaz, M., Herrero, M., García, L.A., et al., 2010. Application of flow cytometry to industrial microbial bioprocesses. Biochem. Eng. J., 48(3):385-407. [doi:10.1016/j.bej.2009. 07.013]

Duetz, W.A., Witholt, B., 2004. Oxygen transfer by orbital shaking of square vessels and deep well microtiter plates of various dimensions. Biochem. Eng. J., 17(3):181-185. [doi:10.1016/S1369-703X(03)00177-3]

Faijes, M., Mars, A.E., Smid, E.J., 2007. Comparison of quenching and extraction methodologies for metabolome analysis of Lactobacillus plantarum. Microb. Cell Fact., 6:27. [doi:10.1186/1475-2859-6-27]

Fonseca, F., Marin, M., Morris, G.J., 2006. Stabilization of frozen Lactobacillus delbrueckii subsp. bulgaricus in glycerol suspensions: freezing kinetics and storage temperature effects. Appl. Environ. Microbiol., 72(10): 6474-6482. [doi:10.1128/AEM.00998-06]

Garbayo, I., Vílchez, C., Vega, J.M., et al., 2004. Influence of immobilization parameters on growth and lactic acid production by Streptococcus thermophilus and Lactobacillus bulgaricus co-immobilized in calcium alginate gel beads. Biotechnol. Lett., 26(23):1825-1827. [doi:10.1007/ s10529-004-5134-3]

Huang, L., Lu, Z., Yuan, Y., et al., 2006. Optimization of a protective medium for enhancing the viability of freezedried Lactobacillus delbrueckii subsp. bulgaricus based on response surface methodology. J. Ind. Microbiol. Biotechnol., 33(1):55-61. [doi:10.1007/s10295-0050041-8]

Jana, S., Lorenz, C.R., Patricia, W., et al., 2009. A method for enzyme quenching in microbial metabolome analysis successfully applied to Gram-positive and Gram-negative bacteria and yeast. Anal. Biochem., 394(2):192-201. [doi:10.1016/j.ab.2009.07.016]

Koek, M.M., Muilwijk, B., van der Werf, M.J., et al., 2006. Microbial metabolomics with gas chromatography/mass spectrometry. Anal. Chem., 78(4):1272-1281. [doi:10. $1021 / \mathrm{ac} 051683+]$

Kumar, S., Wittmann, C., Heinzle, E., 2004. Minibioreactors. Biotechnol. Lett., 26(1):1-10. [doi:10.1023/B:BILE. 0000009469.69116.03]

Lange, H.C., Eman, M., van Zuijlen, G., et al., 2001. Improved rapid sampling for in vivo kinetics of intracellular metabolites in Saccharomyces cerevisiae. Biotechnol. Bioeng., 75(4):406-415. [doi:10.1002/bit.10048]

Li, C., Zhao, J.L., Wang, Y.T., et al., 2009. Synthesis of cyclopropane fatty acid and its effect on freeze-drying survival of Lactobacillus bulgaricus L2 at different growth conditions. World J. Microbiol. Biotechnol., 25(9): 1659-1665. [doi:10.1007/s11274-009-0060-0]

Link, H., Anselment, B., Weuster-Botz, D., 2008. Leakage of adenylates during cold methanol/glycerol quenching of Escherichia coli. Metabolomics, 4(3):240-247. [doi:10. 1007/s11306-008-0114-6] 
Meyer, H., Liebeke, M., Lalk, M., 2010. A protocol for the investigation of the intracellular Staphylococcus aureus metabolome. Anal. Biochem., 401(2):250-259. [doi:10. 1016/j.ab.2010. 03.003]

Nielsen, J., 1997. Metabolic control analysis of biochemical pathways based on a thermokinetic description of reaction rates. Biochem. J., 321:133-138.

Oldiges, M., Lütz, S., Pflug, S., et al., 2007. Metabolomics: current state and evolving methodologies and tools. Appl. Microbiol. Biotechnol., 76(3):495-511. [doi:10.1007/ s00253-007-1029-2]

Otto, R., Brink, B., Veldkamp, H., et al., 1983. The relation between growth rate and electrochemical proton gradient of Streptococcus cremoris. FEMS Microbiol. Lett., 16(1): 69-74. [doi:10.1111/j.1574-6968.1983.tb00261.x]

Russell, J.B., Diez-Gonzalez, F., 1998. The effects of fermentation acids on bacterial growth. Adv. Microb. Physiol., 39:205-234. [doi:10.1016/S0065-2911(08)60017-X]

Schädel, F., David, F., Franco-Lara, E., 2011. Evaluation of cell damage caused by cold sampling and quenching for metabolome analysis. Appl. Microbiol. Biotechnol., 92(6): 1261-1274.

Schaefer, U., Boos, W., Takors, R., et al., 1999. Automated sampling device for monitoring intracellular metabolites dynamics. Anal. Biochem., 270(1):88-96. [doi:10.1006/ abio.1999.4048]

Schiraldi, C., Valli, C., Molinaro, A., et al., 2006. Exopolysaccharides production in Lactobacillus bulgaricus and Lactobacillus casei exploiting microfiltration. J. Ind. Microbiol. Biotechnol., 33(5):384-390. [doi:10.1007/ s10295-005-0068-x]
Siegumfeldt, H., Rechinger, K.B., Jakobsen, M., 2000. Dynamic changes of intracellular $\mathrm{pH}$ in individual lactic acid bacteria cells in response to a rapid drop in extracellular pH. Appl. Environ. Microbiol., 66(6):2330-2335. [doi:10. 1128/AEM.66.6.2330-2335.2000]

Spura, J., Reimer, L.C., Wieloch, P., et al., 2009. A method for enzyme quenching in microbial metabolome analysis successfully applied to Gram-positive and Gram-negative bacteria and yeast. Anal. Biochem., 394(2):192-201. [doi:10.1016/j.ab.2009.07.016]

Tang, Y.J., Martin, H.G., Myers, S., et al., 2009. Advances in analysis of microbial metabolic fluxes via ${ }^{13} \mathrm{C}$ isotopic labeling. Mass Spectrom. Rev., 28(2):362-375. [doi:10. 1002/mas.20191]

van Dam, J.C., Eman, M.R., Frank, J., et al., 2002. Analysis of glycolytic intermediates in Saccharomyces cerevisiae using anion exchange chromatography and electrospray ionisation with tandem mass spectrometric detection. Anal. Chim. Acta, 460(2):209-218. [doi:10.1016/S00032670(02)00240-4]

Villas-Bôas, S.G., Bruheim, P., 2007. Cold glycerol-saline: the promising quenching solution for accurate intracellular metabolite analysis of microbial cells. Anal. Biochem., 370(1):87-97. [doi:10.1016/j.ab.2007.06.028]

Wittmann, C., Krömer, J.O., Kiefer, P., et al., 2004. Impact of the cold shock phenomenon on quantification of intracellular metabolites in bacteria. Anal. Biochem., 327(1): 135-139. [doi:10.1016/j.ab.2004.01.002]

Wu, H., Southam, A.D., Hines, A., et al., 2008. Highthroughput tissue extraction protocol for NMR- and MSbased metabolomics. Anal. Biochem., 372(2):204-212. [doi:10.1016/j.ab.2007.10.002]

\section{中文概要:}

\section{本文题目：保加利亚乳杆菌代谢组学中淬灭方法的优化研究}

Optimization of the quenching method for metabolomics analysis of Lactobacillus bulgaricus

研究目的：为保加利亚乳杆菌的代谢组学研究提供一种简单有效的淬灭方案。

创新要点: 采用适当的淬灭技术是获得微生物真实代谢物组数据的必要条件。本研究首次建立了适用于 保加利亚乳杆菌代谢组学研究的淬灭方法, 有助于完善乳酸菌代谢的生理学和遗传学概貌。

研究方法: 分别应用 $-40{ }^{\circ} \mathrm{C}$ 的 $60 \%$ 甲醇/水、 $80 \%$ 甲醇/水和 $80 \%$ 甲醇/甘油三种方式淬灭保加利亚乳杆菌。 利用光密度 (OD) 回收率实验、流式细胞术和气质联用（GC-MS）分析菌体细胞完整性和细 胞内外代谢物，以及主成分分析法（PCA）和正交偏最小二乘法-判别分析法（OPLS-DA）分 析代谢物泄露程度。

重要结论： $80 \%$ 冷甲醇/水更适用于淬灭保加利亚乳杆菌, 能有效减少代谢物泄露程度和增加胞内代谢物 水平。

关键词组: 代谢组学; 淬灭处理; 保加利亚乳杆菌; 泄露 